\title{
Is the Use of Sealing and Hemostatic Agents Justified in Hepatic Resections? Review and Meta-analysis
}

\author{
Andrea Boscà Robledo*, Ana Navío Seller, Mireia Navasquillo Tamarit, Javier Maupoey \\ Ibáñez, Raquel Jiménez Rosellón, Eva María Montalvá Orón, Rafael García Domínguez, \\ David Calatayud Mizrahi and Rafael López Andújar
}

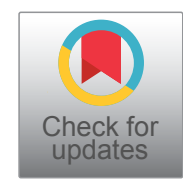

Hepatobiliary Pancreatic Surgery and Transplantation Unit, La Fe University and Polytechnic Hospital, Spain

\begin{abstract}
The use of biological hemostatic and sealing agents over the edge of the liver resection has been increasing exponentially for over 30 years but without solid literature review.

The aim of this study was to produce a meta-analysis including only prospective and randomized studies to know real effect using hemostatic sealants on the resection edge after elective hepatic resection, especially regarding biliary fistula and hematoma.

A literature search of the Medline and EMBASE was carried out to find prospective and randomized trials related to the use of hemostatic sealant in the surface of the liver resection compared with not using products after the usual revision of hemostasis.

Six studies were included involving a total of 1002 patients in this meta-analysis. After analysing the results, the risk of developing hematoma/abscess or biliary leak was not related to the use of sealants. Odds Ratio [OR]: 1.19; $95 \%$ confidence interval $[\mathrm{Cl}]: 0.79-1.81 ; \mathrm{p}=0,40$ and $\mathrm{OR}: 1.02 ; 95 \% \mathrm{Cl}: 0.65-1.61 ; \mathrm{p}=0.92$ respectively.

The use of sealants over the edge of the liver resection does not currently provide any benefit and its cost is not really justified.
\end{abstract}

\section{Keywords}

Hemostatic agents, Hepatic resections, Biliary fistula, hemostasis

\section{Introduction}

The improvements in surgical techniques and anaesthetic management have reduced postoperative mortality in hepatic surgery in the last years, reaching rates between $0.7 \%$ and $2.6 \%$ [1]. However, morbidity remains high, exceeding in some series $50 \%$ [1]. Morbidity due to the edge of the hepatic section, such as hematomas and biliary fistulas, remains a grievous problem that in the end consumes more resources, leads to longer hospital stays and even increases mortality [2]. The estimated incidence of bleeding is between $4.2-10 \%$ and of biliary fistula is between $4-17 \%$ [3-4]. In addition, hepatic resections on a pathological liver as consequence of chemotherapy drugs, such as steatohepatitis, or Sinusoidal Obstruction Syndrome or even on a cirrhotic liver with thrombocytopenia and coagulation defects, increase the possibilities of complications, especially bleeding [5].

That is why, the use of biological hemostatic and sealing agents over the edge of the liver resection has been intensified for over 30 years, with the aim of decreasing the need for blood transfusion, decreasing bleeding and biliary fistulas
[6]. Indeed, over half of the centers performing hepatic surgery systematically employ these agents, with no specific indications nor scientific evidence endorsing their use [7].

There are three different kinds of hemostatic agents [1, 8-9]:

- Collagen, cellulose or gelatin-matrix with no active products to help the coagulation cascade. Hemostatic agents made of fibrillar or microfibrillar collagen attract platelets and help with forming the clot. Cellulose or gelatin, or

*Corresponding author: Andrea Boscà Robledo, Hepatobiliary pancreatic Surgery and Transplantation Unit, 106 Avenue Fernando Abril Martorell, La Fe University and Polytechnic Hospital, 46026 Valencia, Spain

Accepted: July 15, 2021

Published online: July 17, 2021

Citation: Robledo AB, Seller AN, Tamarit MN, et al. (2021) Is the Use of Sealing and Hemostatic Agents Justified in Hepatic Resections? Review and Meta-analysis. J Healthcare 4(1):39-45 
polysaccharides spheres matrix form a mechanical barrier that causes protein unfolding.

- Active products that replicate the coagulation cascade such as fibrine sealants, which are made from fibrinogen combined with thrombin and constitute an insoluble reticular fibrin matrix. In order to stabilize the clot, some antifibrinolytic agents may be present. The composition of the clot varies according to the composition of the hemostatic agent. For example, the more fibrinogen, the thicker the clot, but it takes longer to form, whereas if it is rich in thrombin, the clot will develop faster but will be weaker.

- The association of both: combining matrix with active products (carrier-bound fibrin sealants), which can be solid (collagen matrix covered by fibrinogen and thrombin) or liquid (thrombin + gelatin or thrombin + collagen).

The aim of this paper is to produce a meta-analysis including only prospective and randomized studies to know whether using hemostatic sealants on the resection edge after elective hepatic resection can help decrease the incidence of bleeding and biliary fistula within the immediate postoperative period compared to traditional hemostatic methods without additional products.

\section{Methods}

A literature search was performed using Medline and Embase database by two independent reviewers, with no language nor time restrictions, to find prospective and randomized trials related to the use of topical hemostatic agents in hepatic surgery, excluding non-randomized trials, retrospective or case-control studies or series of cases.

The following terms were used: "fibrin sealant", "fibrin glue" combined with "liver resection", "liver surgery", "hepatic resection", "hepatic surgery" and "bile leakage". In addition, studies identified by being cited in these publications were included. The same keywords were used to search the Cochrane library, in the review and Cochrane protocol departments, as well as the clinical trials, editorials and special collections.

Inclusion criteria were based on the PICO schema that includes: elected patients and their characteristics, intervention employed versus the one evaluated and the wanted result.

Patients included in the studies underwent minor or major elective liver resections, for benign or malignant diseases and including open and laparoscopic surgery. Articles analyzing the results of surgical interventions different from hepatic resection, excluding liver transplantation and split liver transplantation, combined-organ surgery or those happening in pediatric patients or animal studies were excluded.

The intervention performed is the use of a hemostatic sealant in the surface of the liver resection after revising hemostasis following the usual clinical practice in hepatic surgery (clips, CUSA, ties, electrocautery, electro-sealing devices); compared to the use of no products after the usual revision of hemostasis. Thus, studies that compare both groups of hemostatic agents with no control group are also excluded.
The results that must be included in the studies are the development of the most frequent complications: both hematoma and biliary fistula.

In addition, the Jadad scale [10], which easily assesses the methodological quality of experimental studies, was used to evaluate the quality of the articles included in the analysis. It consists of three items: randomization, the blinding method and the description of abandonment and loses during the follow-up period. The items suggested by the Cochrane database for systematic reviews were used to appraise risk of bias (which are classified in three groups: low risk, high risk and obscure risk) [11]:

- Randomized generation of the sequence to avoid selection bias.

- Hiding the assignation to avoid selection bias.

- Blinding the participants and the investigators to avoid performance bias.

- Blinding the outcome assessors to avoid detection bias.

- Incomplete results due to withdrawals from the study to avoid attrition bias.

- Selective reporting of the results (reporting bias).

The statistical analysis in quantitative variables was performed calculating the mean difference with the standard deviation by the inverse variance using the fixed effects model. In cases of qualitative variables, percentages were used also adopting the fixed effects model. Heterogeneity was evaluated using the $\mathrm{c}$ test $^{2}$ and the I statistic ${ }^{2}$. A low heterogeneity level was defined as $I^{2}<25 \%$ associated to a $p$ value of $\geq 0.10$.

\section{Results}

The initial search strategy based on Medline and Embase database identified 189 studies, from which animal studies and articles including procedures different from elective hepatic surgery were excluded. Articles comparing over 2 different hemostatic agents, or studies with no control group were excluded, as well as non-randomized prospective trials. Finally, 6 studies including a total of 1004 patients were selected, where using a sealing hemostatic agent was prospectively and randomly compared to using no agents on the surface of the hepatic resection (Figure 1). The main characteristics of the articles included are shown in Table 1 [12-17].

The included studies can be considered to be of moderate quality (shown in Figure 2). Although blinding the surgeon is not possible, patients were not informed whether they received the sealing agent or not. The randomization sequence is well described in 3 out of the 6 studies and follow-up loses are not clearly described in any of them, as shown in the Jadad scale (Table 2).

All 6 articles describe the apparition of hematoma or abscess in both study groups, a total of 1002 patients. The risk of developing abscess was not related to the use of sealants (OR 1.19; Cl 95\% $0.79-1.81$ ) according to the fixed effects model $(p=0.40)$, with no heterogeneity between the studies (Figure 3). 


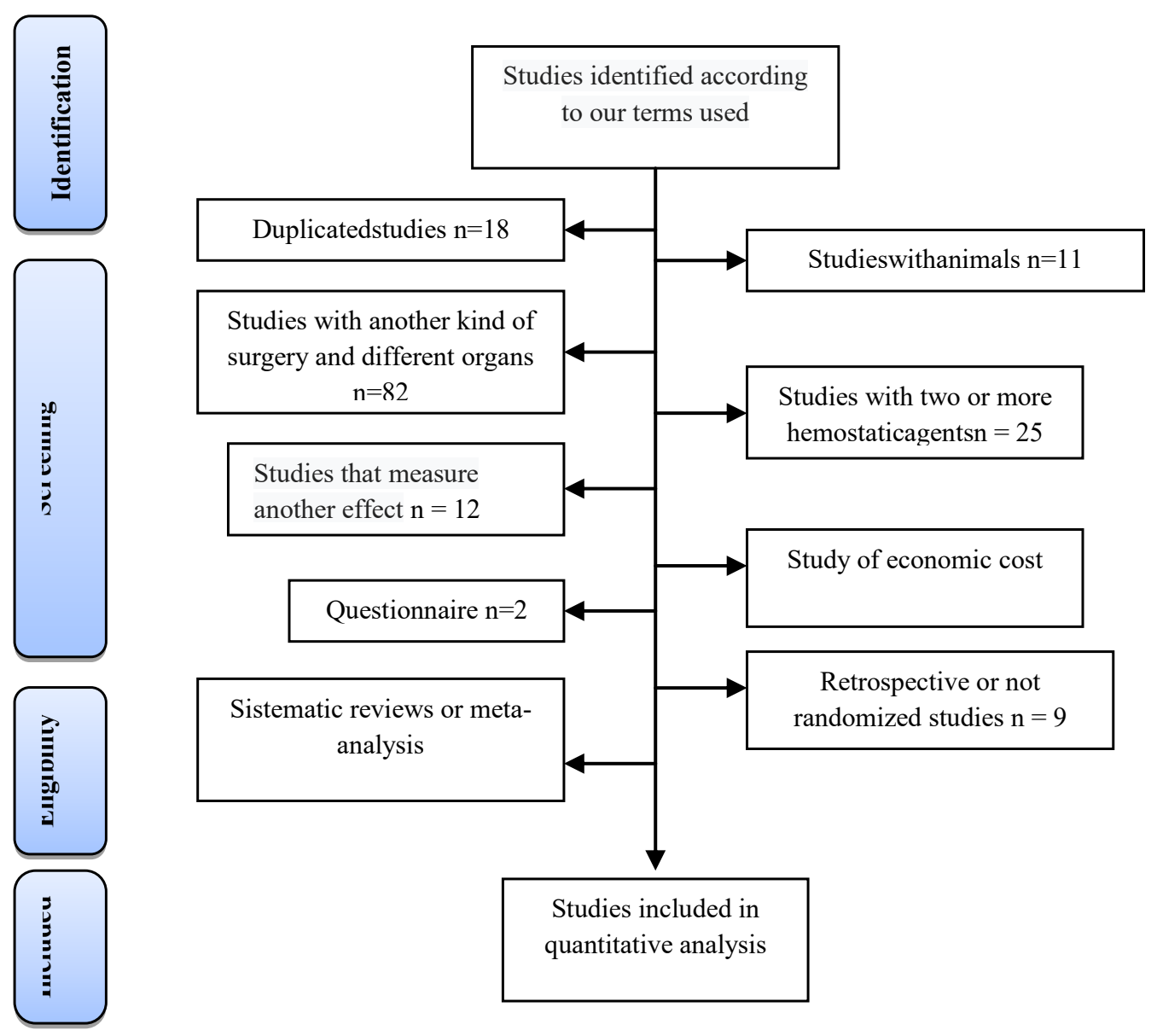

Figure 1: Flow chart of study search, selection, and inclusion. Search strategy for PubMed: (((Liver resection [Title/Abstract]) or liver surgery [Title/Abstract]) or Hepatic resection [Title/Abstract]) and adult [MeSH]) and fibrin sealant [Title/Abstract]) or fibrin glue [Title/Abstract]) or bile leakage [Title/Abstract].

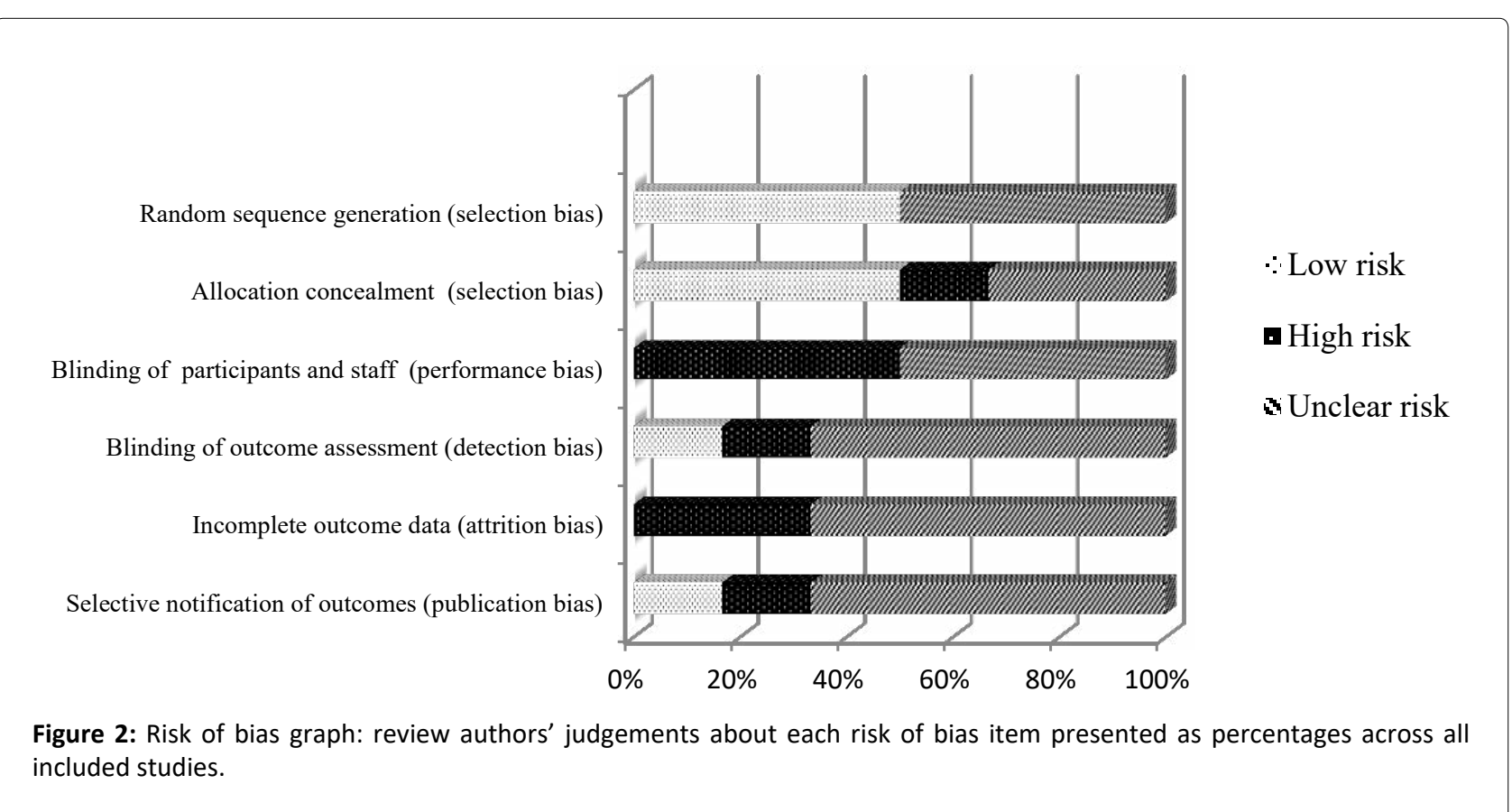


Citation: Robledo AB, Seller AN, Tamarit MN, et al. (2021) Is the Use of Sealing and Hemostatic Agents Justified in Hepatic Resections? Review and Meta-analysis. J Healthcare 4(1):39-45

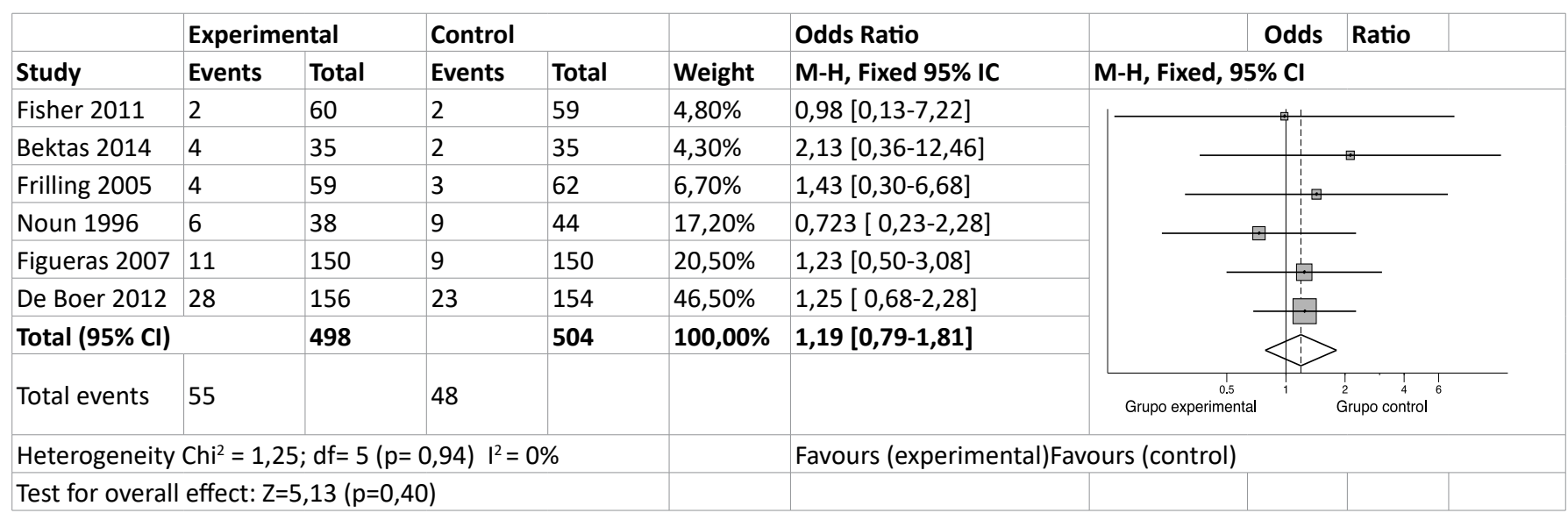

Figure 3: Forest plot comparing intra-abdominal abscess from six trials. A Mantel-Haenszel fixed-effects model is used and Odds Ratios are shown with $95 \%$ confidence intervals.

Table 1: Characteristics of included randomized controlled trials. SD: standard deviation; EG: experimental group; CG: control group; FS: fibrin sealant.

\begin{tabular}{|c|c|c|c|c|c|c|c|}
\hline $\begin{array}{l}\text { Author and } \\
\text { year }\end{array}$ & Country & Intervention (n) & $\begin{array}{l}\text { Age } \\
\text { (mean } \pm \text { SD) }\end{array}$ & $\operatorname{Sex}(M / F)$ & $\begin{array}{l}\text { Abscess/ } \\
\text { haemathoma }\end{array}$ & Biliaryleak & Mortality \\
\hline $\begin{array}{l}\text { Bektas [12] } \\
2014\end{array}$ & German & $\begin{array}{l}\text { CG: Manual compresion (35) } \\
\text { EG: FS.(35) }\end{array}$ & $\begin{array}{l}\text { CG: } 59,8 \pm 12,8 \\
\text { EG: } 54,7 \pm 14,5\end{array}$ & $\begin{array}{l}\text { CG: } 19 / 16 \\
\text { EG: } 20 / 15\end{array}$ & $\begin{array}{l}\text { CG: } 3(8,6 \%) \\
\text { EG: } 0(0,0 \%)\end{array}$ & $\begin{array}{l}\text { CG: } 3(8,6 \%) \\
\text { EG: } 4(11,4 \%)\end{array}$ & $\begin{array}{l}\text { CG: } 1(2,9 \%) \\
\text { EG: } 1(2,9 \%)\end{array}$ \\
\hline $\begin{array}{l}\text { De Boer [13] } \\
2012\end{array}$ & Nederland & $\begin{array}{l}\text { CG: No FS }(154) \\
\text { EG: Crosseal }{ }^{\circ}(156)\end{array}$ & $\begin{array}{l}\text { Median (RIQ) } \\
\text { CG: } 61 \text { (51-69) } \\
\text { EG: } 62 \text { (53-68) }\end{array}$ & $\begin{array}{l}\text { CG: } 76 / 78 \\
\text { EG: } 83 / 73\end{array}$ & $\begin{array}{l}\text { CG: } 12(8 \%) \\
\text { EG: } 10(6 \%)\end{array}$ & $\begin{array}{l}\text { CG: } 21(14 \%) \\
E G: 22(14 \%)\end{array}$ & $\begin{array}{l}\text { CG: } 2(1 \%) \\
\text { EG: } 11(7 \%)\end{array}$ \\
\hline $\begin{array}{l}\text { Figueras[14] } \\
2007\end{array}$ & Spain & $\begin{array}{l}\text { CG: No FS (150) } \\
\text { EG: Tissucol }{ }^{\circ}+\text { Absorbable } \\
\text { collagen sponges }(150)\end{array}$ & $\begin{array}{l}\text { CG: } 60 \pm 11 \\
\text { EG: } 62 \pm 11\end{array}$ & $\begin{array}{l}\text { CG: } 46 / 104 \\
\text { EG: } 59 / 91\end{array}$ & $\begin{array}{l}\text { CG: } 8(5 \%) \\
\text { EG: } 9(6 \%)\end{array}$ & $\begin{array}{l}\text { CG: } 17(11 \%) \\
E G: 15(10 \%)\end{array}$ & $\begin{array}{l}\text { CG: } 2(1 \%) \\
\text { EG: } 6(4 \%)\end{array}$ \\
\hline $\begin{array}{l}\text { Fischer [15] } \\
2011\end{array}$ & Germany & $\begin{array}{l}\text { CG: Argon beam coagulation } \\
\text { (59) } \\
\text { EG: Tachosil }{ }^{\bullet}(60)\end{array}$ & $\begin{array}{l}\text { CG: } 62 \pm 11,7 \\
\text { EG: } 60 \pm 12,6\end{array}$ & $\begin{array}{l}\text { CG: } 30 / 21 \\
\text { EG: } 40 / 27\end{array}$ & $\begin{array}{l}\text { CG: } 1(1,7 \%) \\
\text { EG: } 1(1,7 \%)\end{array}$ & Not available & $\begin{array}{l}\text { CG: } 4(6,8 \%) \\
\text { EG: } 2(3,3 \%)\end{array}$ \\
\hline $\begin{array}{l}\text { Frilling [16] } \\
2005\end{array}$ & Sweden & $\begin{array}{l}\text { CG: Argon beam coagulation } \\
\text { (62) } \\
\text { EG: Tachosil }{ }^{\circ}(59)\end{array}$ & Not available & Not available & $\begin{array}{l}\text { CG: } 3(5 \%) \\
\text { EG: } 4(7 \%)\end{array}$ & $\begin{array}{l}\text { CG: } 2(3 \%) \\
\text { EG: } 4(7 \%)\end{array}$ & $\begin{array}{l}\text { CG: } 2(3,2 \%) \\
\text { EG: } 6(10,2 \%)\end{array}$ \\
\hline $\begin{array}{l}\text { Noun }[17] \\
1996\end{array}$ & France & $\begin{array}{l}\text { CG: No FS (44) } \\
\text { EG: Biocol' }(38)\end{array}$ & $\begin{array}{l}\text { CG: } 49 \pm 15 \\
\text { EG: } 52 \pm 15\end{array}$ & $\begin{array}{l}\text { CG: } 20 / 24 \\
\text { EG: } 24 / 14\end{array}$ & $\begin{array}{l}\text { CG: } 9(20,5 \%) \\
\text { EG: } 6(15,8 \%)\end{array}$ & Not available & Not available \\
\hline
\end{tabular}

Table 2: Jadad Scale.

\begin{tabular}{|l|c|c|c|c|c|c|}
\hline & \multicolumn{5}{|c|}{ Jadad Scale } \\
\cline { 2 - 7 } & Noun 1996 & Frilling 2005 & Figueras 2007 & Fischer 2011 & De Boer 2012 & Bektas 2014 \\
\hline $\begin{array}{l}\text { Randomization method described and } \\
\text { appropriate }\end{array}$ & 1 & 2 & 2 & 2 & 2 \\
\hline $\begin{array}{l}\text { Double-blinding method described and } \\
\text { appropriate }\end{array}$ & 0 & 0 & 0 & 0 & 0 \\
\hline $\begin{array}{l}\text { Description of withdrawals and dropouts } \\
\text { Total Score }\end{array}$ & 1 & 0 & 2 & 1 & 0 \\
\hline
\end{tabular}

The number of biliary leaks analysed within 801 patients from the 4 studies showed no significant differences between both groups (OR 1.02; $\mathrm{Cl} 95 \%$ 0.65-1.61) according to the fixed effects model $(p=0.92)$ and all the studies were homogeneous (Figure 4).

Complete data about total volume of drainage of biliary fistula is only shown in two studies and no relevant differences were found, with non-significant mean difference $(-175.68 \mathrm{ml}$; Cl 95\% -367.66-16.31) (Figure 5). There were no differences either in the rate of patients needing blood transfusion in both groups, $14.82 \%$ in the experimental group and $12.36 \%$ in the control group required a blood transfusion.

Only two studies show complete data about hospital stay, and there were no significant differences in the mean hospital stay between both groups (-0.05 days in favour of the experimental group; $\mathrm{Cl} 95 \%-1.60-1.49, \mathrm{p}=0.95$.

Mortality was evaluated within the first 30 postoperative days, being higher in the experimental group, where a hemostatic agent was placed, OR 2.17; IC 95\% 1.01- 4.66, $p=0.05$. 
Citation: Robledo AB, Seller AN, Tamarit MN, et al. (2021) Is the Use of Sealing and Hemostatic Agents Justified in Hepatic Resections? Review and Meta-analysis. J Healthcare 4(1):39-45

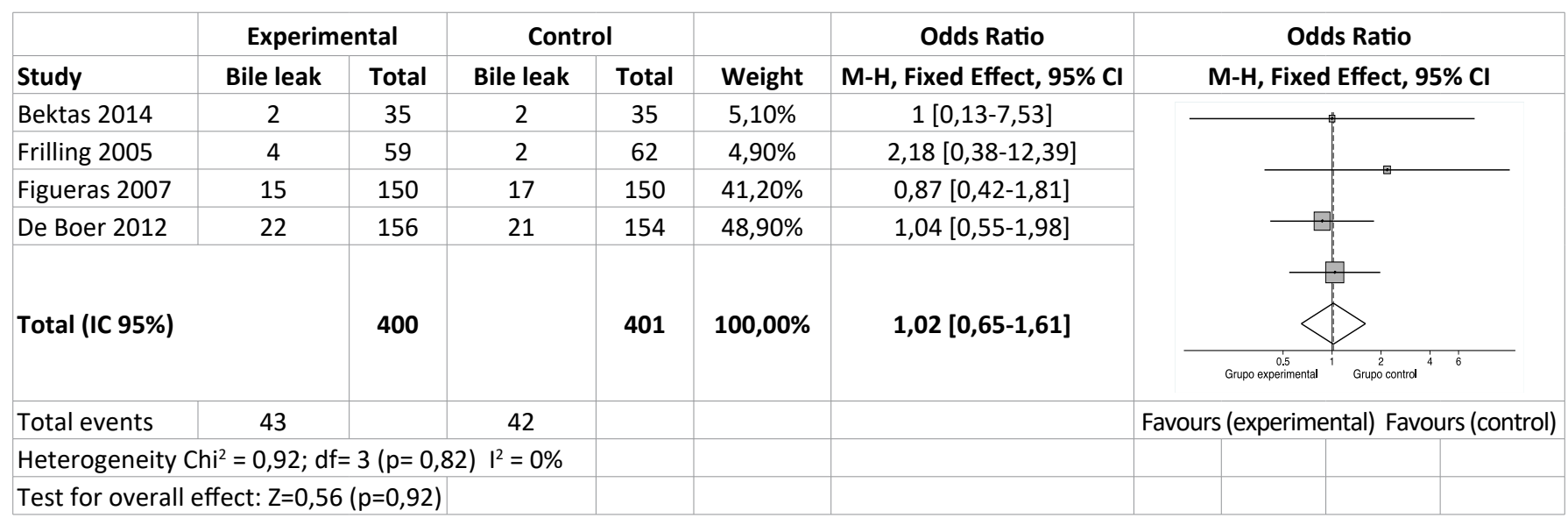

Figure 4: Forest plot comparing bile leak from four studies following the use of sealant and control. A Mantel-Haenszel fixed-effects model is used and Odds Ratios are shown with $95 \%$ confidence intervals.

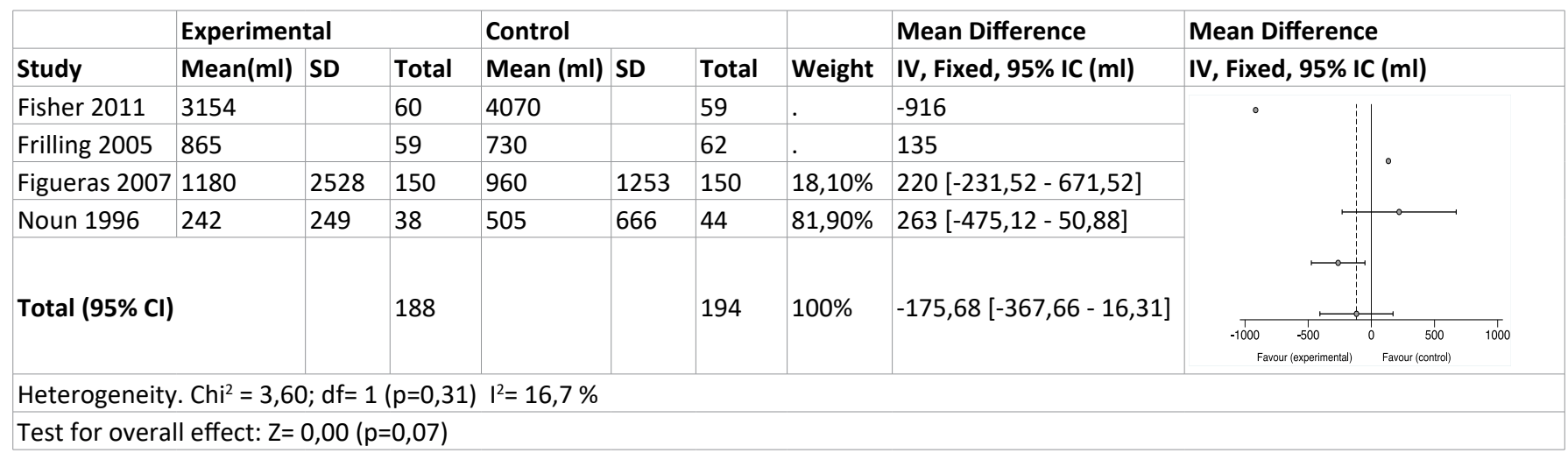

Figure 5: Forest plot comparing the volume of drainage from four studies. A fixed-effects model with inverse variance method is used. Mean differences are shown with $95 \%$ confidence intervals

\section{Discussion}

Many different sealing agents have appeared within the last years; so using hemostatic agents is becoming increasingly popular. These products are very expensive, but are not sufficiently endorsed by the evidence-based literature. Most of the studies involving sealants include few patients, combining several types of surgical procedures and most are retrospective non-randomized studies. In hepatic surgery, high quality studies exclusively analysing its use against using no hemostatic agent to control bleeding and biliary leaks remain few.

Using sealing and hemostatic agents in liver resection has been already evaluated in other reviews and metaanalysis. However, low quality studies were included and the systematic use of these products could not be routinely recommended. In addition, some of the most recent and influential publications that fall under the randomized prospective trials are non-inferiority studies between several products with no control group, increasing heterogeneity between studies. Moench, et al. [18] and Olliger, et al. [19], for example, compare hemostatic agents made of collagen or cellulose matrix to matrix combined with active products with no control group. In these cases, combined matrix superiority cannot be demonstrated either.

The main aim of these studies is not very clinically relevant, for example, Bjelović, et al. [20] measure the time needed for hemostasis, which depends on every assessor. There are barely any differences between sealing agents according to the results, however, does that mean a decreased blood loss or a decrease in the number of blood transfusions? The answer to this question remains no, the clinical impact cannot be demonstrated yet.

Figueras, [14] et al. 2007 is one of the most potent articles according to methods. Both study groups presented acceptable size sample (150 patients in each group to obtain a minimum $30 \%$ differences in complications), randomization was performed adequately; and was compared to the control group to find out whether there were any real advantage and if it should be routinely used. In the end, there was no evidence supporting its use to avoid bleeding, transfusions and complications, biliary fistula. Newer products keep appearing daily and hepatic surgeons keep using them with no justified criteria, because of the greater companies pressure.

Sanjay, et al. [21] remain one of the most outstanding meta-analysis, which consists only of prospective randomized trials, however, it includes comparisons between different hemostatic agents and different endpoints. The results showed no significant differences between both groups in hemostasis time, postoperative bleeding, biliary leak, morbidity and mortality. Some years later, Brustia, et al. [1] in 2016 redacted a meta-analysis with studies including different hemostatic agents and between hemostatic agents and 
manual compression, including however, prospective studies, retrospective studies and case control trials. However, the time before reaching hemostasis was between 2-6 minutes, something subjective, and not very relevant in today's clinical practice.

In 1996, previous to all these studies 1996 Moggia, et al. [22] published a meta-analysis with the aim of studying factors that helped diminish blood loss in hepatic resection. In these cases, fibrin sealants showed minimum and little relevant differences. Also, an increase in the fresh plasma transfusion was observed in the group that consist of cellulose matrix, but the difference was minimal and only 2 studies were used.

Due to all the different points of view previously documented, in order to be able to answer the question of using sealants in hepatic resection a new meta-analysis was needed. Minimum requirements included only studies with randomized prospective trials, with a lone experimental group; where hemostatic and sealing agents are used, and a control group. Studies comparing different products were excluded due to increased confusion. One of the limitations of the analysis is that although sealants with similar characteristics have been used, not all commercial brands use the same active ingredients. The primary endpoints should be clinically important, such as biliary leak, morbidity, intraabdominal abscesses and mortality, only including elective hepatic surgery and excluding liver transplantation both from cadaveric donor and life donor.

Our results are based on a well-designed data analysis, which is indicative of high quality. One of the reasons why using sealants is becoming increasingly popular is that it lessens bleeding or intraabdominal abscesses, something we have not been able to prove. All of the 1002 analysed patients presented the same risk of developing a postoperative abscess if undergoing treatment with the sealing as to using no product over the resection margin. The same happens with the problem of the biliary fistula.

Citing again Moggia's meta-analysis neither confirmed nor denied the presence of less bleeding when using the sealants, and no patients underwent blood transfusion during postoperative course [22].

Another limitation is that the drainage output was difficult to analyse since registration was not uniform in the different studies.

Rough data shows twice the mortality in the group treated with sealing agents ( 20 cases to 10 ), since the risk's IC is much too close to 1 , it cannot be considered as a meaningful (OR 2.17; $\mathrm{Cl}$ 1.01-4.66), even though the trend presents increased mortality in patients treated with sealing agents.

Finally, this meta-analysis has shown that using sealing agents on the liver resection margin dos not bring any benefits currently. None of the analysed items displayed significant differences between using them or not, so the cost of these products is not really justified. More studies with strong methodologically quality are needed, and also studies including its price and economic costs, in order to rationalize their use or adjust their indications.

\section{Conflicts of Interest}

The Authors have no Conflicts of Interest.

\section{References}

1. Brustia R, Granger B, Scatton O (2016) An update on topical haemostatic agents in liver surgery: systematic review and meta analysis. J Hepatobiliary Pancreat Sci 23: 609-621.

2. Cauchy F, Aussilhou B, Dokmak S, et al. (2012) Reappraisal of the risks and benefits of major liver resection in patients with initially unresectable colorectal liver metastases. Ann Surg 256: 746-752.

3. Yamashita Y, Hamatsu T, Rikimaru T, et al. (2001) Bile leakage after hepatic resection. Annals of Surgery 233: 45-50.

4. Jin S, Fu Q, Wuyun G, et al. (2013) Management of posthepatectomy complications. World Journal of Gastroenterology 19: 7983-7991.

5. Khan AZ, Morris-Stiff G, Makuuchi M (2009) Patterns of chemotherapy-induced hepatic injury and their implications for patients undergoing liver resection for colorectal liver metastases. J Hepatobiliary Pancreat Surg 16:137-144.

6. Huntington JT, Royall NA, Schmidt CR (2014) Minimizing blood loss during hepatectomy: a literature review. J Surg Oncol 109: 81-88.

7. Kraus TW, Mehrabi A, Schemmer P, et al. (2005) Scientific evidence for application of topical hemostats, tissue glues, and sealants in hepatobiliary surgery. J Am Coll Surg 200: 418-427.

8. Saif R1, Jacob M, Robinson S, et al. (2011) Use of fibrin-based sealants and gelatin-matrix hemostats in laparoscopic liver surgery. Surg Laparosc Endosc Percutan Tech 21: 131-141.

9. Hanna EM, Martinie JB, Swan RZ, et al. (2014) Fibrin sealants and topical agents in hepatobiliary and pancreatic surgery: a critical appraisal. Langenbecks Arch Surg 399: 825-835.

10. Jadad AR, Moore RA, Carroll D, et al. (1996) Assessing the quality of reports of randomized clinical trials: is blinding necessary? Controlled Clinical Trials 17: 1-12.

11. Higgins JPT, Altman DG, Sterne JAC (2011) Chapter 8: Assessing risk of bias in included studies. En: Higgins JPT, Green S. Cochrane Handbook for Systematic Reviews of Interventions Version 5.1.0. The Cochrane Collaboration.

12. Bektas H, Nadalin S, Szabo I, et al. (2014) Hemostatic efficacy of latest-generation fibrin sealant after hepatic resection: a randomized controlled clinical study. Langenbecks Arch Surg 399: 837-847.

13. De Boer MT, Klaase JM, Verhoef C, et al. (2012) FRESCO Trial Group. Fibrin sealant for prevention of resection surfacerelated complications after liver resection: a randomized controlled trial. Ann Surg 256: 229-234.

14. Figueras J, Llado L, Miro M, et al. (2007) Application of fibrin glue sealant after hepatectomy does not seem justified: results of a randomized study in 300 patients. Ann Surg 245: 536-542.

15. Fischer L, Seiler CM, Broelsch CE, et al. (2011) Hemostatic efficacy of TachoSil in liver resection compared with argon beam coagulator treatment: an open, randomized, prospective, multicenter, parallel-group trial. Surgery 149: 48-55.

16. Frilling A, Stavrou GA, Mischinger $\mathrm{HJ}$, et al. (2005) Effectiveness of a new carrier-bound fibrin sealant versus argon beamer as haemostatic agent during liver resection: a randomised prospective trial. Langenbecks Arch Surg 390: 114-120. 
17. Noun R, Elias D, Balladur $P$, et al. (1996) Fibrin glue effectiveness and tolerance after elective liver resection: a randomized trial. Hepato gastroenterology 43: 221-224.

18. Moench C, Mihaljevic AL, Hermanutz V, et al. (2014) Randomized controlled multicenter trial on the effectiveness of the collagen hemostat Sangus top compared with a carrierbound fibrin sealant during liver resection (ESSCALIVER study, NCT00918619). Langenbecks Arch Surg 399: 725-733.

19. Ollinger R, Mihaljevic AL, Schuhmacher C, et al. (2013) A multicentre, randomized clinical trial comparing the Veriset haemostatic patch with fibrin sealant for the management of bleeding during hepatic surgery. HPB (Oxford) 15: 548-558.
20. Bjelović M, Ayguasanosa J, Kim RD, et al. (2018) Investigators of the Fibrin Sealant Grifols in Hepatic Resection Clinical Investigation Study Group. A Prospective, Randomized, Phase III Study to Evaluate the Efficacy and Safety of Fibrin Sealant Grifols as an Adjunct to Hemostasis as Compared to Cellulose Sheets in Hepatic Surgery Resections. J Gastrointest Surg 22: 1939-1949.

21. Sanjay P, Watt DG, Wigmore SJ (2013) Systematic review and meta-analysis of haemostatic and biliostatic efficacy of fibrin sealants in elective liver surgery. J Gastrointest Surg 17: 829-836.

22. Moggia E, Rouse B, Simillis C, et al. (2016) Methods to decrease blood loss during liver resection: a network meta-analysis. Cochrane Database Syst Rev 10: CD010683. 